\title{
Atacameños y aymaras. El desafío de la "verdad histórica"
}

Claudia Zapata $S .^{1}$

\section{RESUMEN}

En este artículo se analiza la presencia de atacameños y aymaras en la Comisión de Verdad Histórica y Nuevo Trato, respondiendo a las preguntas de cómo se plantean frente al tema de la historia y cómo resuelven el desafio de presentar una versión propia de ella. La primera parte consiste en una síntesis histórica de la relación que se ha establecido entre el Estado chileno y las poblaciones indígenas del Norte Grande, mientras que en la segunda se presenta el análisis de los documentos que asumen una representatividad atacameña y aymara en esta Comisión, elaborados por líderes y miembros de organizaciones en conjunto con profesionales e intelectuales no indígenas. El núcleo de nuestra aproximación está en la visualización de la historia como herramienta política y el intento de los actores por posicionarse en ella, con las contradicciones y tensiones que este esfuerzo implica.

Palabras claves: identidad - discurso - historia - memoria.

\section{ABSTRACT}

This paper analyzes the presence of Atacameños and Aymaras in Chile's Historical Truth and New Deal Commission, answering questions concerning how these peoples relate to the topic of History and how they resolve the challenge of presenting a historical version of their own. The first part is a synthesis of the chronological relationship between the Chilean State and indigenous populations in Northern Chile. The second part renders the analysis of the documents that were presented in representation of the Atacameños and Aymara in this Commission, which were elaborated by leaders and members of indigenous organizations along with nonindigenous professionals and intellectuals. Our approach is centered on a view of History as a political tool, and in the attempts agents make to position themselves in it, with the tensions and contradictions this effort implies.

Key words: identity - discourse - History - memory.

Recibido: abril 2004. Manuscrito revisado aceptado: agosto 2004.

1 Centro de Estudios Culturales Latinoamericanos, Facultad de Filosofía y Humanidades, Universidad de Chile. Ignacio Carrera Pinto 1025, Ñuñoa, Santiago, CHILE. Email: escufilo@uchile.cl

\section{Introducción}

En enero del año 2001 el Presidente de la República, Ricardo Lagos, emitió un decreto con el cual se constituía la Comisión de Verdad Histórica y Nuevo Trato, la cual tendría por objetivo elaborar una propuesta nacional para resolver los temas pendientes con la población indígena. Con esta iniciativa se dio cumplimiento a una de las primeras promesas que hizo Lagos tras asumir la presidencia en marzo del año $2000 .^{2}$ A su vez, la Comisión significó una continuidad con la política de los dos gobiernos anteriores de la Concertación de Partidos por la Democracia hacia este sector de la población, identificado a partir de 1990 como destinatario de políticas específicas y de un "nuevo trato".

Esta Comisión aparece a 10 años del retorno a la democracia y siete de haberse aprobado por unanimidad la Ley Indígena. Contrario al clima de consensos de aquella época, fue planteada en medio de una fuerte tensión social en la región de la Araucanía, donde una parte del movimiento mapuche radicalizó sus posiciones políticas y sus estrategias de movilización. Este paso del optimismo a la confrontación y la desconfianza da cuenta de la inconformidad surgida entre las organizaciones indígenas de las distintas etnias que aparecen reconocidas en la Ley Indígena, quienes no han visto la materialización de este nuevo trato.

Fiel al estilo de hacer política que se inauguró a partir de $1990,{ }^{3}$ esta iniciativa surgió como el re-

2 Me refiero a la "Carta Pública a los Pueblos Originarios" emitida en mayo de ese año. En ella, Lagos proponía 16 medidas para abordar la situación de los pueblos indígenas. La primera era constituir esta comisión, cuya propuesta de organización recayó en la CONADI y en el Ministerio de Planificación y Cooperación ("Ministerios asumen compromiso con Pueblos Originarios", www.conadi.cl).

3 Caracterizada por la búsqueda de consensos y la participación de sectores de la sociedad civil especialmente convocados en cada instancia propuesta por el gobierno, lo que 
sultado de una mesa de diálogo, convocada por el gobierno e integrada por miembros de la sociedad civil. Fue presidida por el ex presidente Patricio Aylwin y estuvo integrada por intelectuales, ministros, representantes de iglesias, empresarios y políticos. ${ }^{4}$ Participaron también miembros de las etnias aymara, atacameña, colla, quechua, mapuche, pehuenche, huilliche y rapa nui. Su objetivo era hacer una revisión histórica de la relación entre estas etnias y el Estado chileno, con el fin de elaborar un diagnóstico y una propuesta que oriente la política del Estado hacia una estrategia de incorporación adecuada de estos grupos a la sociedad nacional. El presidente Lagos definió este proyecto en los siguientes términos:

\section{“(...) la tarea de esta Comisión no es solamente} mirar lo que ocurrió, sino también orientarnos y dar ideas hacia el futuro. Su objetivo es crear las bases como dice el Decreto, para una política de Estado respecto de los pueblos originarios, que valore, respete e incorpore la cosmovisión de cada uno de ellos a nuestra propia realidad". 5

Propuestas gubernamentales de este tipo son sintomáticas de la importancia que ha adquirido el tema de la situación en que se encuentran los pueblos indígenas al interior de los Estados nacionales. No se trata de una concesión solamente, sino una de las respuestas posibles al protagonismo que han alcanzado aquellos movimientos que desarrollan una acción política desde posiciones identitarias, en este caso indígena. En América Latina este fenómeno ha sido particularmente intenso, con la irrupción de movimientos en varios países de la región desde fines de los años '70, lo que ha hecho de la identidad étnica

desde la óptica oficialista implicaría participación ciudadana y profundización de la democracia. Si bien constituye un mecanismo que distancia a la Concertación del autoritarismo pinochetista, se trata de una participación aceptada y promovida en la medida que sea encauzada por canales institucionales, en los cuales se escucha a las partes pero se terminan imponiendo las decisiones del gobierno (determinadas por las negociaciones con el bloque político opositor).

4 Este proceso es relatado por Cristián Maquieira, representante permanente alterno de Chile ante Naciones Unidas. Intervención en el "Programa de actividades del Decenio Internacional de las Poblaciones Indígenas del Mundo", Nueva York, 17 de octubre de 2002 (www.un.int/chile/Discursos).

5 Ricardo Lagos, 18 de enero de 2001 (www.presidencia.cl). un eje político imposible de ser obviado, tanto por los círculos intelectuales como por los gobiernos de estos países. Esto se produce en un contexto mundial en el que existe una sensibilidad especial sobre el tema de la diversidad, lo cual ha contribuido a visualizar grupos culturalmente distintos y a la creación de identidades articuladas en torno al principio de la diferencia. ${ }^{6} \mathrm{~A}$ esta discusión se han incorporado los gobiernos de los países democráticos, como un intento por insertarse en este nuevo contexto, pero también como una forma de abordar sus propios conflictos internos. Las palabras del presidente Lagos en el discurso citado son una muestra de este clima cultural y político:

"Invité a vivir la riqueza de la diversidad cultural que es lo que da forma a Chile. Por la naturaleza de las cosas, todas las culturas de Chile tienen un derecho y un lugar. Tienen derecho a acceder a la sociedad del conocimiento de sus valores, con sus costumbres, con su arte y su espiritualidad; a sentirse parte de la comunidad, pero a partir de su propia identidad [...] Esto es lo que corresponde a un país culto, a un país civilizado y a un país democrático. Es la tendencia que predomina en nuestro mundo contemporáneo, donde el respeto a los derechos humanos surge como el nuevo lenguaje común universal".

En Chile el retorno a la democracia y la acción de una clase política que incorporó este tema a su agenda dio un perfil particular al proceso, al encauzar por canales institucionales un movimiento indígena que se encontraba en una etapa inicial, sin alcanzar por entonces la amplitud y la presencia pública de otros en el continente, ${ }^{7}$ pero que compartía con estos el giro de asumir en forma positiva la categoría de "indio", aceptando y promoviendo una diferencia cultural de la que se sienten portadores.

Aunque esta Comisión tuvo una restricción inicial pues poseía un carácter solamente proposi-

\footnotetext{
6 Posibilitado por un marco de relaciones distintas a las que predominaron durante gran parte del siglo XX, cuyos rasgos predominantes son una estructura económica que se ha modificado en el capitalismo tardío en aras de una mayor interconexión de mercados y una situación política en que se perdió el referente del socialismo.

7 Entre ellos los de Bolivia, Ecuador y México, por nombrar a los que han alcanzado mayor impacto político.
} 
tivo, ${ }^{8}$ resulta interesante que se plantee el tema de la historia como el eje de la discusión, en torno al cual se articularon otros como el de la reparación y las políticas gubernamentales. Esta importancia dada a la historia parte de un hecho relevante: la constatación de que los relatos oficiales y sus versiones escolares son insuficientes y reduccionistas, en este caso por la ausencia del sujeto indígena en la historiografía nacional. De ahí la necesidad de conocer estas otras voces e incorporarlas al espacio público, con el objetivo de avanzar hacia explicaciones más complejas de la relación entre los pueblos indígenas y el Estado chileno. Así se señala en el primer artículo del Decreto que crea la Comisión:

"Créase la Comisión de Verdad y Nuevo Trato, destinada a asesorar al Presidente de la República, en el conocimiento de la visión de nuestros indígenas sobre los hechos históricos de nuestro país y a efectuar recomendaciones para una nueva política de Estado, que permita avanzar hacia el nuevo trato de la sociedad chilena y su reencuentro con los pueblos originarios". 9

Lo que se presenta en las siguientes páginas es una reflexión sobre el tema de la verdad histórica a partir de los planteamientos que hacen las propias organizaciones aymaras y atacameñas sobre ella, por lo tanto, el análisis estará centrado en la lectura de los documentos elaborados en el marco de esta Comisión: informes preliminares, documentos de trabajo e intentos de síntesis que buscan articular una historia propia y entrelazarla con las demandas que actualmente dirigen al Estado. Previo a esto, es indispensable revisar el contexto histórico de las relaciones entre la nación chilena y los grupos indígenas del Norte Grande, con el fin de situar el momento actual en que tanto el Estado como estos grupos han experimentado desplazamientos importantes en la forma de abordar esta relación.

8 "Ustedes no están aquí para buscar soluciones concretas a los problemas y demandas actuales de los pueblos indígenas. Esa es tarea del gobierno. Ustedes están aquí para conocernos y reconocernos mejor..." (Ricardo Lagos, discurso presidencial, 18 de enero de 2001).

9 Comisión de Verdad Histórica y Nuevo Trato. Secretaría Ejecutiva, Decreto Supremo No 19, 18 de enero de 2001.

\section{Las poblaciones indígenas del Norte Grande y su relación con el Estado chileno. Una retrospectiva histórica}

En el contexto latinoamericano, la nación chilena aparece como una de las que se constituyó y consolidó más tempranamente. La historiografía oficial sostiene que el tránsito breve y poco traumático de la Colonia a la República explicaría ese grado mayor de estabilidad que distinguiría a Chile.

Sin negar el hecho de que tras la independencia no se produjeron las luchas intestinas prolongadas de otros países de la región, esta imagen de armonía y progresiva consolidación corresponde en gran medida a una elaboración de la historiografía del siglo XIX y la corriente conservadora del siglo XX (heredera de muchas de las premisas decimonónicas). ${ }^{10}$ La historiografía más reciente ha buscado revertir esta imagen, colocando énfasis en las complejidades y contradicciones de este proceso. En primer lugar, señalando su naturaleza autoritaria, pues obedeció a los lineamientos de la élite que se instaló en el poder político, la cual concebía a la nación chilena a partir de parámetros modernos clásicos que imponían los criterios de unidad, homogeneidad e integridad del territorio, a partir de los cuales se autoasignaron la misión de definir, excluir y establecer sus límites tanto simbólicos como territoriales. ${ }^{11}$

En América Latina -y Chile no fue la excepciónhubo dificultades para implementar un proyecto que tenía tales referencias teóricas. ${ }^{12}$ Lo que sal-

10 Germán Colmenares, en un iluminador estudio sobre la historiografía decimonónica de los países hispanoamericanos, identifica un canon en el que existían técnicas de figuración de la realidad, con las cuales se articulaba el relato histórico. Una de ellas era la continuidad narrativa, usada con la finalidad política de ocultar las rupturas y conflictos sociales que trajo consigo la implementación de estos proyectos, tendiendo sobre ellos un manto de estabilidad y armonía (Colmenares 1997: 35).

11 Es importante considerar la presencia de estos principios clásicos en torno a la nación, no como un marco teórico sobre el tema sino por el peso ideológico que ha tenido, pues a partir de ella se ha tendido a "leer la nación", como ha sido el caso de América Latina, donde todavía se presenta con extraordinaria vigencia.

12 Esta tradición clásica se desarrolla principalmente durante el siglo XIX y tiene variantes importantes en el contexto europeo (la corriente francesa y la alemana son ejemplos), pero a grandes rasgos se resume y canoniza en la célebre 
taba a la vista era que no se estaba frente a una situación dada sino al desafío de su construcción, emprendida por la élite desde la posición del Estado. La férrea unión conceptual que se estableció desde entonces entre Estado y nación no es mera retórica, pues, aunque son conceptos que refieren a configuraciones históricas diferentes, nuestra historia republicana los unió en un proyecto específico (el de la élite), pues fue el Estado el lugar desde el cual se buscó generar las condiciones para implementarlo (Palti 2003:145).

La historiografía aparece como uno de los mecanismos ideológicos fundamentales en esta construcción, dando forma a las narrativas nacionales. Las historias "patrias" -siguiendo la conceptualización de Colmenares (1997)- se dieron a la tarea de articular un pasado que señalara la superioridad de la nación independiente, de ahí la ruptura con el Período Colonial, la relevancia de la independencia y el rechazo hacia todo lo que escapara a los principios de homogeneidad cultural y progreso. ${ }^{13}$

En el transcurso del siglo XIX estos supuestos sobre los cuales se erigió este imaginario de nación se vieron fuertemente problematizados. El momento más crítico se vivió con la expansión territorial, momento en que el Estado chileno se anexó -a través de conflictos bélicos- la zona de la Araucanía y una extensa superficie en el norte. Fue un momento en que "lo indio" dejó de estar fuera, para pasar a incorporarse como minorías étnicas. Martínez y colaboradores (2003) señalan que esta expansión implicó una reformulación de los imaginarios nacionales a fines de esa centuria, refiriéndose también a los casos de Bolivia, Perú y Argentina, países que también experimentaron la modificación de sus fronteras territoria-

conferencia de Ernest Renan, leída en La Sorbona en 1882, con el sugerente título de ¿Qué es una nación?, en la cual resumió estos principios y señaló a la nación como el último y más elevado escalón de la organización humana, al cual sólo pueden llegar los pueblos que estén aptos para ello y del cual Francia, su país natal, constituía el mejor ejemplo (texto publicado en Fernández Bravo 2000: 53-66).

13 Sobre esto apunta Colmenares: "No requiere hurgar demasiado en los textos historiográficos del siglo XIX para encontrarse con una hostilidad manifiesta hacia lo más autóctono americano, hacia lo indígena y hacia las castas. El fastidio hacia lo rústico y elemental de las masas campesinas iletradas se convertía en franca repulsión cuando se trataba de indígenas, mulatos y mestizos" (1997: 20). les. En el caso de Chile, se planteó el desafío de integrar a estas poblaciones en la historia nacional. El caso de los grupos indígenas andinos es interesante justamente por esta incorporación tardía y el conflicto de nacionalidades que implicó durante las primeras décadas. Lo más llamativo de esta propuesta es que postula la importancia de las poblaciones indígenas en tanto referentes de lo que se quería y no se quería ser como nación. Durante el siglo XIX se apostó por un distanciamiento, pero el ejercicio mismo de comparación implicó la incorporación de la categoría "indio" al pensamiento moderno, desprendiéndola del pasado colonial que -se asumía- la nación había cancelado, entendiéndola como una posición inferior, pero desde la cual era posible iniciar el tránsito hacia la modernidad (Gundermann 2003: 56-57).

En el Norte Grande, la incorporación de estos vastos territorios implicó establecer una presencia concreta por parte del Estado. La ocupación de los espacios marginales se fue dando de manera paulatina, siendo las tierras altas las últimas en quedar bajo un control más permanente. Pero esta ocupación no estuvo ausente de problemas. J. L. Martínez menciona el caso de la Puna de Atacama a fines del siglo XIX, lugar donde se confrontaron tres lógicas de dominio: las de Chile, Bolivia y Argentina. Chile se habría interesado principalmente en los territorios y sus recursos (sobre la población caían sospechas de "extranjería"), mientras que Bolivia se habría inclinado más bien por la población, sometida entonces a tributo indígena (Martínez 1994: 203). Por su parte, el interés de Argentina tenía que ver con la posición estratégica de esta zona dada su proximidad con la costa del Pacífico.

En las regiones anexadas se desarrolló un capitalismo de enclave en torno a la explotación de recursos mineros (primero el salitre y luego el cobre). La zona norte fue pionera en la introducción de este modelo de producción, lo cual significó transformaciones de la mayor importancia, que afectaron todos los ámbitos de la existencia de sus habitantes, un fenómeno del cual las poblaciones indígenas no quedaron al margen. ${ }^{14}$

\footnotetext{
14 Este ha sido un tema ampliamente trabajado, sobre el cual existe acuerdo en señalar la adecuación de la economía agraria tradicional que desarrollaban las comunidades indígenas, especialmente de las zonas altas, quienes se vincu-
} 
El proceso de "chilenización" se inició a principios del siglo XX, pero se intensificó a partir de los años '30, con el acceso de los sectores medios al gobierno. En condiciones nacionales y mundiales diferentes (tras la Primera Guerra Mundial y la crisis de 1929), se inauguró el largo y azaroso período del Estado de bienestar, que va a promover la integración de las masas populares. ${ }^{15} \mathrm{En}$ este contexto social y político es que el Estado fortalece su presencia en el norte, con obras de infraestructura, la escuela pública y servicios de salud, aunque débil todavía en relación con otras zonas del país. Sería recién durante la dictadura militar cuando esta presencia se extendió y consolidó en los lugares más apartados, aunque no a partir de este ideal integrador, sino del principio de seguridad nacional y reforzamiento de fronteras.

¿Cuál fue la reacción de las poblaciones indígenas en todo este proceso? La literatura especializada se pronuncia ampliamente, con un énfasis en la "embestida" del Estado contra los indígenas, quienes -según el autor y la corriente que representevivirán la desestructuración de su mundo tradicional, o bien, desarrollarán una resistencia que les permite mantener espacios importantes de éste. J. L. Martínez defiende la tesis de una participación más activa de la que usualmente se reconoce, sin negar la interrelación de estas poblaciones con la sociedad nacional y regional sino partiendo de ella como premisa de análisis. ${ }^{16}$ Para Martínez (1994: 201), durante los momentos conflictivos se manifiesta una dinámica política de negociación por parte de estas poblaciones (refiriéndose a las comunidades altoandinas de Atacama), como habría ocurrido cuando Chile, Argentina y Bolivia disputaban el control sobre la zona de Atacama, momento en que estas comunidades manejaron la opción de ser chilenas.

laron al ciclo salitrero a través del abastecimiento de estos centros con insumos menores, para lo cual reactivaron el arrieraje e iniciaron el cultivo de alfalfa (Rivera 1999; Núñez 1992). Con el tiempo y especialmente durante el ciclo del cobre, se intensificó la inserción como mano de obra en las faenas productivas.

15 Esto significó nuevamente la reformulación de los imaginarios nacionales en varios países de América Latina tras la crisis del modelo de crecimiento oligárquico (la llegada del Frente Popular al gobierno de Chile es más o menos contemporánea a la consolidación del PRI en México, del Varguismo en Brasil y del Peronismo en Argentina).

16 En oposición a una conceptualización de la resistencia indígena vinculada con el aislamiento y la negativa al cambio.
Para el período 1930-1970, Gundermann complejiza todavía más esta relación, señalando que estas poblaciones optaron por el proyecto de integración que se planteó desde el Estado, lo cual significaba asumir sus premisas, entre ellas la condición de ciudadano. Lo señala también como una respuesta a la permanencia social de una imagen negativa y estigmatizada de los indios:

"Sostenemos que la identidad nacional y, en concordancia con la anterior, la identidad política de la ciudadanía, es el tipo de identificación a la que las poblaciones indígenas regionales, ahora aymaras y atacameñas, por largo tiempo han optado volcarse, buscando trascender la condición infamante de 'indio"' (Gundermann 2003: 52).

\section{La búsqueda del reconocimiento étnico}

En la actualidad, la demanda de estos grupos tiene como eje articulador el principio de la diferencia. Así, quienes hoy se reconocen como aymaras y atacameños reclaman el derecho a sostener públicamente una pertenencia étnica, así como a mantener y desarrollar aquellas prácticas sociales y culturales que los distinguen de la cultura nacional y la sociedad chilena en general, a la cual buscan integrarse desde esta diferencia.

Considerando la postura que en general desarrollaron estos grupos durante gran parte del siglo $\mathrm{XX}$, argumentos de este tipo representan un momento de ruptura más que de continuidad histórica. De ahí la importancia de considerar la trayectoria de esta relación, brevemente señalada en el apartado anterior, pues permite sustentar la idea de que esta etapa actual de organización nos coloca frente a un sujeto indio nuevo, resultado de una construcción identitaria reciente, de los años '80 en el caso aymara y de principios de los ' 90 en el atacameño (Gundermann 2000). Para Martínez, la construcción de estas identidades corresponde a otro intento de negociación con la sociedad mayor. Sobre los atacameños señala:

"Me refiero al actual resurgimiento de una identidad étnica, la atacameña, que involucra a comunidades y pobladores que hasta hace pocos años atrás la hubiesen negado, pero que parece ser necesaria (o al menos, así es vista), para renegociar frente al Estado (y la Comisión Especial de Pueblos Indígenas), una posición -nuevamente- más expectante" (1994: 206). 
Gundermann (2000 y 2003) rastrea los inicios de este fenómeno, indicando la importancia que tuvo la formación de una élite profesional en el caso aymara (por lo general urbanos de origen altiplánico) y los dirigentes de las comunidades atacameñas a principios de los ' 90 , cuando el ambiente nacional y la acción del Estado en particular promovieron este tipo de identificaciones.

Para entender esta transformación resulta útil conceptualizarla a partir de un enfoque que considere las identidades en tanto construcciones dinámicas y dialógicas, ${ }^{17}$ pues no son fenómenos que ocurran en un aislamiento difícil de sostener para el caso que aquí se está tratando, sino, al contrario, la historia regional demuestra que la trayectoria de estos grupos se encuentra marcada por la migración, la movilidad ${ }^{18}$ y la inserción en los circuitos económicos regionales. Esto hace cada vez más difícil sostener juicios como la permanencia de la comunidad tradicional y la existencia de identidades aymaras y atacameñas de larga data, los que confrontados con este marco regional carecen de sustento histórico. ${ }^{19}$

Las identidades aymara y atacameña aparecen como una práctica social en la que se postula la diferencia cultural como experiencia válida y relevante, un lazo de unión entre quienes adhieren a ella. Koonings y Silva, recogiendo algunos trabajos clásicos de la antropología, señalan los pilares sobre los cuales se articula la identidad étnica:

17 El concepto de etnogénesis es clave en estos enfoques constructivistas, pues indica justamente el carácter relacional, contingente y en permanente cambio de las identidades étnicas (Stavenhagen 2000: 24-25).

${ }_{18}$ Recojo este concepto de la antropóloga E. Alber (1999), para quien el de migración resulta insuficiente en el período actual, cuando una parte importante de la población andina mantiene residencias simultáneas que hacen difícil sostener la oposición entre lo urbano y lo rural.

19 Sin embargo, sorprende la vigencia de corrientes académicas de corte primordialista en el estudio de las poblaciones indígenas andinas y en general de América Latina (Koonings y Silva 1999: 11). Para el caso que estoy tratando esta corriente se manifiesta en dos variantes que comparten, en mayor o menor medida, un trasfondo esencialista. Por una parte se encuentra una visión romántica, que postula la permanencia y resistencia de lo andino a pesar de los embates modernizadores, y por otra, una de corte más fatalista, que supone a esta población en un polo tradicional (no occidental) amenazado por el contacto con la sociedad nacional.
'La 'etnicidad' se refiere específicamente a la identificación de una colectividad social a partir de antecedentes históricos, la existencia de un pasado común, la identificación con un territorio, el uso de un mismo idioma, junto a otros elementos culturales y simbólicos compartidos por los miembros de esta colectividad" (1999: 5-6).

En ambos casos estos antecedentes son difíciles de identificar y unificar, o incluso, de establecer su existencia histórica. Por ejemplo, el idioma de los atacameños ya no existe y el territorio es muy difícil de definir si consideramos la gran movilidad de la población indígena en esta zona ${ }^{20}$, lo cual se dificulta todavía más en la actualidad, con un segmento urbano que reivindica estas identidades (se debe incluir también a los aymaras) sin la base de un territorio ancestral de residencia. Esto no significa que no exista la diferencia cultural que ellos invocan, pero estas dificultades son indicadoras de la voluntad de imaginarse como totalidad, pasando por alto diferencias que en otros tiempos sirvieron para distanciarlos (Martínez 1994: 206). Este acto de voluntad colectiva resulta fundamental, pues la identidad étnica no es la consecuencia directa de la diferencia cultural, un punto sobre el cual insiste Gundermann:

“ (...) en contra de una visión de sentido común, las diferencias culturales objetivas entre dos grupos no son el único aspecto relevante de la etnicidad y de la identidad. Se deben anteponer criterios subjetivos de identificación, autoadscripción y pertenencia. Sólo en la medida en que las diferencias culturales son percibidas como importantes y que son hechos socialmente relevantes es que las relaciones sociales tienen un componente étnico" (2003: 29).

Otros actores en el surgimiento de la identidad aymara y atacameña

La importancia de la interacción radica en que el surgimiento de estas identidades no es el resultado de un esfuerzo endógeno, sino de una confluencia de voluntades con otros actores, lo cual no hace más que indicar su naturaleza dialógica. En

\footnotetext{
20 Se señala incluso la dificultad de nombrar lo atacameño en términos de unidad étnica y territorial (Castro y Martínez 1996)
} 
primer lugar corresponde mencionar al Estado, que, como se dijo, también ha sido relevante en la formulación de otras identidades a lo largo del siglo XX entre estas poblaciones. Hoy, esa importancia se repite tras la llegada al gobierno de la Concertación de Partidos por la Democracia, cuyos personeros políticos -o por lo menos una parte importante de ellos- habían incorporado el tema de la diversidad cultural a su visión de la transición a la democracia y estaban en la línea de la reparación histórica con los grupos indígenas, promoviendo discusiones de este tipo entre las organizaciones y comunidades.

Tras la elección presidencial de 1989, algunas premisas del multiculturalismo pasaron a formar parte del lenguaje político del ahora sector oficialista. Una versión algo descuidada en términos teóricos y con poco impacto en la idea misma de nación, pero que ha significado la creación de una institucionalidad (primero la CEPI y luego la CONADI) y la destinación de una cantidad importante de recursos para financiar las políticas de discriminación positiva contenidas en la Ley Indígena. Todo ello ha conformado un escenario favorable para una acción más desenvuelta de las organizaciones indígenas ya existentes o bien para la conformación de otras, las que no han sido reacias a involucrarse en el proceso, principalmente a través de la CONADI.

Esto ha implicado un desplazamiento importante en la posición gubernamental respecto a las poblaciones indígenas, el que tiene como punto de partida reconocer su existencia como grupos diferenciados culturalmente, a los cuales se considera necesario dirigir políticas específicas. Esto ha producido una movilización que ha seguido caminos insospechados a los que promovió esta parte de la clase política. Un ejemplo es el debate en torno al reconocimiento, en el que una parte importante de las organizaciones indígenas ha desplazado sus demandas al ámbito político, siguiendo la tendencia continental de los movimientos indígenas.

Por otra parte, y en un nivel regional, cabe destacar la acción de otros actores, principalmente de algunos académicos y ONG (Gundermann 2000). Su relevancia va más allá de un mero acompañamiento, pues han sido vitales en la formulación de una identidad positiva en torno a la categoría de "indio", así como en la definición y los contenidos de sus demandas. Son vínculos que están presentes en la discursividad que han producido tanto aymaras como atacameños, los cuales se filtran en los documentos producidos por las organizaciones durante toda la década de los '90 (la mayoría incentivados por el gobierno y sus instancias de mediación), fenómeno que se repite en aquellos que fueron elaborados para la Comisión de Verdad Histórica y Nuevo Trato.

\section{Atacameños y aymaras en la Comisión de Verdad Histórica y Nuevo Trato}

\section{El corpus de documentos}

Aunque ya se indicó en la introducción de este trabajo, es oportuno insistir en que se trata de documentos elaborados en el marco de una instancia oficial convocada por el gobierno, lo cual obliga a circunscribir el análisis en ciertos parámetros. Por ejemplo, que no agotan toda la discursividad que han producido atacameños y aymaras a lo largo de esta última década, sino que representan un momento específico de ella. También que su carácter de documentos públicos y el énfasis en los acuerdos al interior de cada grupo (un esfuerzo que busca la sistematización representativa de sus demandas) constituyen un filtro para la heterogeneidad discursiva que existe al interior de cada uno.

Los documentos seleccionados para este análisis son aquellos que asumen una representación indígena, motivo por el cual su principal característica es un lugar de enunciación que parte de un "nosotros" atacameño o aymara. Sin embargo, esta idea de lo propio no debe hacernos perder de vista la importancia de la mediación no indígena en todo el proceso de producción, interacción que constituye uno de los rasgos más sobresalientes de lo que Bengoa (2000) ha denominado "emergencia indígena” en toda América Latina.

Los dirigentes de las organizaciones han jugado un papel fundamental en la elaboración de estos documentos. Su formación y los vínculos que han establecido con los actores regionales los coloca en un nivel más sofisticado del debate, en lo que también ha influido el contacto con los planteamientos de otros movimientos indígenas y la incorporación de argumentos indianistas que circu- 
lan en distintas redes de información. ${ }^{21}$ Estos dirigentes forman parte de la élite de estos grupos, compuesta por líderes y profesionales que han sido claves en la construcción de una identidad general ("aymara", "atacameño", "indígena") colocada por sobre el localismo que ha caracterizado a esta población y con la cual coexiste (no necesariamente de manera articulada). Sin embargo, la debilidad de estas élites es un factor que debe ser considerado en el análisis de su producción discursiva, lo que en el plano organizativo se refleja en problemas de representatividad e incluso de legitimidad, como se acusa recurrentemente en el caso aymara. Esto ha redundado en la incapacidad para consolidar un tipo de organización democrática o para generar un compromiso más profundo con demandas de envergadura como la del reconocimiento constitucional de los pueblos indígenas (aunque se menciona, su desarrollo conceptual es insuficiente, lo que a su vez da luces sobre la extensión limitada de esta construcción identitaria). Son élites que desde la década pasada mantienen una demanda permanente por información y capacitación de líderes, llegando al 2003 con reuniones todavía informativas sobre instrumentos básicos como la Ley Indígena. ${ }^{22} \mathrm{Un}$ factor que contribuye a explicar estas deficiencias, es la falta de una intelectualidad que aporte a la reflexión histórica y política, para dar mayor densidad conceptual a una demanda hasta ahora desarticulada y discontinua. ${ }^{23}$

21 Esto ha determinado una característica fundamental de estos documentos: su fuerte intertextualidad, como se demuestra en la inserción de documentos y temas recurridos por los movimientos indígenas (el convenio 169-OIT, la cuestión de la autonomía, etc.), así como de aquellos que han sido claves en su producción discursiva (en el caso aymara, las resoluciones de los congresos nacionales y el Plan Estratégico de Desarrollo Andino, entre otros). Para clarificar, se entiende aquí por intextualidad la referencia reconocida o velada de ideas, autores, organizaciones y textos de distintas épocas (De Toro 1997: 23).

22 Los atacameños declaran saber muy poco de esta ley, mientras que los documentos aymara insisten desde 1996 en la capacitación y formación de líderes (Plan Estratégico de Desarrollo Andino 1997 y Propuesta IV Congreso Nacional Aymara 2002, entre otros).

23 Esto no quiere decir que carezca de una dirección mayor pues si algo unifica la demanda andina de este período es la propuesta de integración a la sociedad nacional desde la diferencia cultural. Sin embargo, se encuentra compuesta por varias vertientes, entre las que destacan una de tipo indianista y otra económico-productiva, con énfasis en el tema del desarrollo. Esta última es la que ha predominado
Sobre el caso particular de esta Comisión, hay elementos del contexto nacional que tampoco es prudente obviar, pues esta iniciativa aparece como una forma de contener la movilización mapuche ascendente que desde 1997 ha desbordado los canales de representación institucional. ${ }^{24}$ En el caso de los indígenas del Norte Grande no se ha producido este nivel de confrontación, pero estos documentos también revelan niveles crecientes de inconformidad. Por este motivo, son sintomáticos de una situación mayor que indica el desgaste de la relación que han mantenido los indígenas y el Estado desde el retorno a la democracia.

\section{La verdad histórica}

La Comisión instala el tema de la historia imponiendo la necesidad de generar consensos como una base sobre la cual sea posible definir políticas. Para los grupos andinos ha sido complejo asumir el compromiso de plantearse en este espacio con una visión propia, pues implicaba el desafío de articular un relato colectivo, coherente y representativo. Una tarea de envergadura mayor en la que las experiencias individuales o de las propias comunidades no resultan suficientes, como lo reconocen las propias organizaciones en los documentos preliminares. Esta exigencia demostró que la historia de cada grupo no era algo preexistente o una situación dada, y más aun, que no existe una memoria atacameña y aymara suficientemente articulada (en los términos de un relato).

La elaboración de una representación histórica propia, que incluya un balance de su existencia al interior del Estado nacional chileno, constituye un paso importante en la consolidación de estas nuevas identidades. "Historizar" la identidad es relevante en la medida que da contenido al discurso

desde los '90, sin dejar de reconocer los avances de la primera, especialmente en los documentos de la Comisión de Verdad Histórica, donde las demandas políticas de corte indianista alcanzan el estatus de "prioritarias".

24 Las palabras de Ricardo Lagos sobre la constitución de esta Comisión contienen una referencia directa a este conflicto: "Este es el único camino para lograr acuerdos. Esta es la manera de solucionar realmente los problemas. El recurso de la violencia siempre conduce a un callejón sin salida. Por ello, es que la abrumadora mayoría de las comunidades indígenas están en este camino, y han aislado a quienes han elegido la violencia. Ese es el elemento determinante que nos debe guiar" (Discurso presidencial, $18 \mathrm{de}$ enero de 2001). 
de la diferencia cultural y también por la importancia política que inevitablemente trae consigo, pues provee la argumentación para respaldar la existencia de derechos, de los cuales a su vez se desprenden demandas, en este caso enfocadas principalmente al desarrollo y a la exigencia de acción estatal.

En los documentos que no tienen la connotación de definitivos (en general, aquellos fechados en el 2002), este relato aparece como un proyecto en etapa muy inicial, como una necesidad pero cuya articulación no se había concretado. En ellos se emiten juicios en los que la historia aparece vista como un dispositivo de poder, el que hasta ahora les ha jugado en contra. ${ }^{25}$ Concretar este objetivo significaría la instalación en un campo conflictivo, donde esta versión se confrontaría con otras, con la particularidad de ser la que destaque sus logros culturales, les reporte dignidad y respalde sus aspiraciones actuales.

Esta elaboración ha implicado la selección de los elementos que desean resaltar de su trayectoria histórica, lo cual es importante, pues indica que no estamos frente a una mera evocación de recuerdos o a un trabajo de recopilación que tenga como única referencia tiempos pretéritos, pues la construcción de una memoria atacameña y aymara tiene objetivos concretos, más relacionados con el tiempo presente que con el pasado remoto. Uno de esos objetivos es hacer plausible el relato y, con ello, la identidad étnica a la cual adscriben, constituyendo una versión propia en la medida que les permita imaginarse y autorreconocerse como colectivos culturales e históricos. Aquí se ubica el valor de este intento, más que en un posible vínculo con la realidad de los hechos narrados. Por lo tanto, más allá de acusar verdad o ficción (todo relato histórico tiene su cuota de cada una por cierto) se coloca énfasis en el concepto de autenticidad (Koonings y Silva 1999: 10) que hace viable para estos grupos una autorrepresentación histórica, como un intento más de diferenciación.

25 No se trata de un planteamiento nuevo y tampoco propio de aymaras y atacameños, como lo demuestra el hecho de recurrir a los acuerdos del Congreso Nacional de Pueblos Indígenas, realizado en Temuco durante el año 1991 ("Sistematización de las demandas indígenas atacameñas", Grupo de Trabajo Pueblos Indígenas del Norte, Subgrupo de Trabajo Pueblo Atacameño, San Pedro de Atacama, abril de 2002, p. 12).
Los documentos preliminares de ambos grupos arrojan características comunes, entre ellas: la identificación de una tradición con el fin de establecer la continuidad entre pasado y presente; la comunidad (tradicional) como eje del análisis; un balance negativo del contacto con el Estado chileno; y finalmente, un intento por marcar distancia con la cultura occidental. Otra igualmente importante y que cruza las anteriores, es el hecho de recurrir a las representaciones académicas sobre cada grupo y sobre el "mundo andino" en general, mostrando predilección por análisis holísticos que les permiten marcar esta distancia con la sociedad nacional y con la modernidad. Hay, entonces, una cercanía con visiones primordialistas que manejan conceptos como los de cosmovisión y comunidad tradicional, paradójico si se contrasta con los soportes que se proponen para una historia propia de atacameños y aymaras, tales como la escritura (se habla de reunir la información dispersa en un "libro"), el archivo y el museo, acompañados de su complemento: las nociones de documento, monumento y patrimonio. Una elección de soportes modernos estrechamente vinculados a la conformación de los Estados nacionales (Lozano 1987; Le Goff 1991).

Una historia “desde" los atacameños. El informe final del Subgrupo Pueblo Atacameño ${ }^{26}$ contiene un extenso "Informe de Verdad Histórica", resultado de las inquietudes y objetivos planteados en los documentos de trabajo elaborados durante el año 2002, en los cuales se había planteado como tarea prioritaria consensuar un relato que relevara los logros culturales del pueblo atacameño, en una versión propia y representativa, que destacara hechos y héroes silenciados por la historia oficial. ${ }^{27}$

Esto concluyó en una versión que destaca por su tono académico, como puede apreciarse en el uso de la nomenclatura arqueológica, antropológica y etnohistórica (conceptos como etnogénesis y autoadscripción son recurrentes en su sección

26 La Comisión está organizada en grupos de trabajo. El Grupo de Trabajo Pueblos Indígenas del Norte se encuentra dividido en cuatro subgrupos: Pueblo Atacameño, Pueblo Aymara, Pueblo Colla y Pueblo Quechua.

27 Objetivos que aparecen en documentos como el Acta Ejecutiva fechada en Ayquina el 10 de mayo de 2002 y otra fechada en San Pedro de Atacama el 20 de mayo de ese mismo año. 
introductoria). Esta interferencia intelectual no indígena es decisiva, pues determina un formato cuidadoso y correcto, que matiza muchos de los planteamientos señalados en los documentos preliminares. Por ejemplo, se declara la necesidad de no incurrir en esencialismos y se incorporan planteamientos de investigaciones recientes que sostienen la dificultad de hablar de lo atacameño como una unidad histórica y espacial. Ahora bien, comentarios de este tipo quedan subordinados al esfuerzo por establecer las continuidades que permitan sostener el protagonismo del pueblo atacameño. Una de ellas es la de la resistencia frente a distintos proyectos de dominio externo: el incaico, el español y el chileno, ${ }^{28}$ señalando como causas de la derrota situaciones externas (las enfermedades en el caso de la conquista española), con las cuales se busca negar la supuesta superioridad cultural y militar de sus oponentes. Este intento por revertir el protagonismo se concreta en el ámbito de los héroes, como se demuestra en el intento por desmitificar a Pedro de Valdivia ${ }^{29}$ e imponer la imagen de un héroe atacameño durante las rebeliones anticoloniales: Tomás Paniri, enviado de Tupac Amaru a la zona de Atacama:

\section{“(...) hacia esa época se realiza en la iglesia de} Chiu Chiu una entrevista entre el líder indígena Tomás Paniri y el representante eclesiástico y en la cual Paniri se presenta con un sable al cinto, instrumento propiamente español y una honda de lana en el pecho, símbolo de la lucha andina". ${ }^{30}$

La cita muestra una de las estrategias discursivas más relevantes de estos documentos, especialmente del Informe Final. Esta consiste en recurrir al conocimiento disciplinario con el fin de articular una memoria de larga duración. En este caso puntual en que se busca discutir el protagonismo abso-

28 Omito el Período Republicano boliviano porque en el texto aparece una curiosa idealización, en el que se vincula a los atacameños con la tradición libertaria americana, representada por Simón Bolívar (Informe Final del Subgrupo de Trabajo Pueblo Atacameño, San Pedro de Atacama, octubre de 2002, pp. 34-35).

29 "De esta forma tenemos que Pedro de Valdivia, comúnmente denominado el Conquistador de Chile, no conquistó la zona de Atacama ya que había enviado a su Capitán de hueste Francisco de Aguirre para realizar tal labor...”. Informe Final del Subgrupo de Trabajo Pueblo Atacameño, San Pedro de Atacama, octubre de 2002, p. 24.

30 Informe Final del Subgrupo de Trabajo Pueblo Atacameño, San Pedro de Atacama, octubre de 2002, p. 33. luto de los dominadores y la pasividad como rasgo indígena, se reconoce la contribución de un historiador como J. Hidalgo (1982), cuya obra permite trabajar en una dimensión temporal profunda y conocer la acción desplegada por la población atacameña en otros momentos de conflicto.

Otra de las continuidades que se busca establecer, es la sobrevivencia de la cultura tradicional atacameña, mermada y acosada por la modernidad, pero existente. Esto se representa en la adopción de la tesis que plantea la existencia de una nación atacameña (Núñez 1992), ${ }^{31}$ que antecedería en miles de años a la chilena. La comunidad se propone como eje del relato, como el lugar donde se desarrolla la resistencia, la reproducción de la cultura tradicional y desde la cual se establece distancia con lo que en este documento se denomina "paradigma occidental", no muy definido pero que para efectos concretos se encuentra personificado en el Estado chileno, identificado como el principal agente de desestructuración del modo de vida ancestral. ${ }^{32}$ La administración chilena aparece analizada en los siguientes términos:

"El modo de vida ancestral comienza un lento proceso de desestructuración y de desarraigo, hecho que repercute notoriamente en las comunidades agropastoriles, transformándose de campesinos, ligados a la hacienda, en obreros asalariados y proletarios [...] En otras palabras, el paradigma occidental que se caracteriza por dividir impacta a las comunidades desarticulando el espacio y sus habitantes, con la eclosión de los núcleos urbanos caracterizados por la pobreza y la marginalidad, como lo demuestran los primeros años de Chuquicamata y Calama". ${ }^{33}$

Lo que aquí se presenta es un modelo de análisis en el que el traslado de población desde las co-

31 Este autor se encuentra presente en toda la narración y en la estructura misma del relato, conservándose la periodización que propone (Núñez 1992).

32 Se insiste en la diferencia con el dominio boliviano anterior a la Guerra del Pacífico, país que habría manifestado mayor preocupación por la población andina: “ (...) el modelo comprensivo integral que caracterizó al mundo andino con las ideas de Bolívar, da paso a un modelo invasivo, individualista, leve y carente del apego ancestral al terruño". Informe Final del Subgrupo de Trabajo Pueblo Atacameño, San Pedro de Atacama, octubre de 2002, p. 41.

33 Informe Final del Subgrupo de Trabajo Pueblo Atacameño, San Pedro de Atacama, octubre de 2002, p. 41. 
munidades hacia las ciudades escapa a sus pautas, pasando a ser entendido sólo en términos de pérdida. Si bien se hace mención al fenómeno de la migración (no así del retorno y de la circulación), este queda en una posición marginal, que no alcanza a plantear la transformación social y cultural como discontinuidad o ruptura con períodos anteriores.

El siglo XX, sobre todo a partir de 1930, es señalado con interés, pues fue el período de los planes de desarrollo regionales más importantes. El desarrollo aparece desde entonces como un tema recurrente, desde el cual se juzga y analiza la política del Estado. A este último se critica la actitud paternalista con las poblaciones indígenas, pero sin llegar a cuestionar la idea misma de desarrollo, manifestándose coherencia entre este tema y las demandas actuales, centradas justamente en el desarrollo de la población atacameña, principalmente rural, a lo cual se incorpora la participación de los atacameños y la consideración de sus necesidades. $^{34}$

El proyecto de una historia aymara. Entre los aymara la elaboración de un informe de verdad histórica se enfrentó a problemas mayores que entre los atacameños, no sólo por una falta de información, sino por la tensión que existe entre sus organizaciones, una divergencia interna protagonizada por líderes con orientaciones ideológicas diferentes. Esta crisis está marcada por un intento de unificación que no se ha consolidado y que al momento de la comisión (2001-2003) se encontraba en franca decadencia. Fue el proyecto que marcó la década de los '90 y que se encuentra representado por el Consejo Nacional Aymara (CNA), surgido del Segundo Congreso Nacional realizado en 1997, el cual ha tratado infructuosamente de monopolizar la representación, asumiéndose como la voz del pueblo aymara. ${ }^{35}$ Esta ten-

34 Esto se impone por los conflictos actuales en torno al agua, originado en un código emitido durante la dictadura que privilegió a los grandes inversionistas mineros. Problema en el cual el Informe Final se pronuncia ampliamente en sus últimas páginas.

35 Esta crisis se manifiesta en el paso de un tono seguro y con cierto sesgo autoritario en los pronunciamientos del CNA (como el que caracteriza a la Propuesta del Pueblo Aymara a los Candidatos Presidenciales, 21 de noviembre de 1999) a otro marcado por la autocrítica (Propuesta IV Congreso Nacional Aymara, Arica, 28 de octubre de 2002). sión cruza el proyecto de una historia aymara en su conjunto, como puede apreciarse en los documentos de trabajo previos, en los que incluso el delicado tema de la representatividad fue puesto en duda.

"No necesariamente todos los planteamientos aquí esbozados son compartidos por todas las organizaciones aymaras, ni siquiera por todos los dirigentes. Lo cierto es que se pueden identificar dos grandes orientaciones en la constitución de la demanda aymara: la una de raigambre campesinista, vinculada a la comunidad local, empeñada en obtener del Estado mejores condiciones para el desarrollo agropecuario y de calidad de vida en el espacio rural; la otra más 'etnicista', representada de manera principal por líderes y organizaciones urbanas surgidas a partir de la década de los ' 80 ". ${ }^{36}$

Si se atiende a este contexto, tanto histórico como el que se dio en el propio Subgrupo de Trabajo Aymara, es posible entender el carácter altamente conflictuado de su relato, lo cual se refleja también en el Informe Final Preliminar que redactaron para la Comisión en enero del 2003. A esta atmósfera enrarecida por la crisis organizacional, quedan supeditados otros problemas relacionados con el tema específico de la historia. Entre ellos, se señala conocer muy poco de la historia aymara, situación que explica a partir de lo que hasta ahora aparece como la línea de análisis preponderante: el de la desestructuración permanente de su cultura, lo cual tendría un correlato negativo en la identidad aymara.

"La mayoría de los participantes en la comisión, ha determinado no conocer bien la historia aymara y la historia andina, por lo cual la identidad se expresa en forma contradictoria [...] La población andina no tiene cabal conciencia de su identidad, sobre todo los aymaras urbanos, quienes por haber nacido en la ciudad ya no se identifican con sus raíces ancestrales". ${ }^{37}$

36 "Sistematización de las demandas y propuestas del pueblo aymara para un nuevo trato", documento de trabajo interno, Subgrupo de Trabajo Pueblo Aymara, Arica, abril de 2002, p. 1.

37 "Sistematización de las demandas y propuestas del pueblo aymara para un nuevo trato", documento de trabajo interno, Subgrupo de Trabajo Pueblo Aymara, Arica, abril de 2002, p. 15. 
Autocríticas de este tipo nos colocan frente a un concepto problemático de cultura que radicaliza posiciones esencialistas, pues se la entiende vinculada a la comunidad, a lo ancestral y al paisaje altiplánico. Imágenes invocadas no sólo por representantes de comunidades sino también por las organizaciones urbanas, cuyos integrantes no tienen la experiencia de la comunidad que idealizan. $^{38}$

Esta noción cerrada de lo aymara -que deja en los márgenes a su mayoría urbana- determina el surgimiento de otro conflicto específico de esta Comisión, el cual se refiere a la autocrítica frente a la falta de recursos para articular un relato propiamente aymara de la historia, tanto conceptuales como en formas de escritura. Aunque valoran el aporte académico, manifiestan inconformidad por no poder concretar por sí mismos esta aspiración. Frente a esta insuficiencia se propuso una solución momentánea, que consistía en "aymarizar" el relato con la incorporación de palabras en su lengua autóctona. ${ }^{39}$ Insatisfacciones de este tipo se reflejan permanentemente en el Informe Final Preliminar, donde la búsqueda (frustrada) de un lenguaje propio aparece como un deseo permanente. ${ }^{40}$

A pesar de estos obstáculos, se valora el proyecto de una verdad histórica, en el cual advierte un potencial político en la medida que se vincule con las demandas que se presentan al interior de la misma Comisión. El objetivo principal fue el de

38 Esto se puede apreciar en la inserción de los acuerdos sobre cultura del II y III Congreso Nacional Aymara en los anexos al documento "Sistematización de las demandas y propuestas del pueblo aymara para un nuevo trato".

39 Esto fue rápidamente rechazado, como quedó establecido en un Acta Ejecutiva: "Parte de la reunión se centró en la discusión sobre la perspectiva en que está escrito el documento (occidental), el cual debería hacerse desde una perspectiva aymara (para reflejar la emotividad y sentimiento del aymara) y no ahora tratar de 'aymarizarlo'. Sin embargo, todos coincidieron en que el tiempo es muy escaso y que el trabajo realizado por autores 'occidentales' hay que mirarlo como un aporte, y reorientar el texto con los recursos y conocimientos como se está haciendo hasta ahora (...)", Arica, 14 de diciembre de 2002, p. 2.

40 Se incorporan palabras aymaras para reemplazar conceptos "chilenos" y occidentales. En cuanto a la metodología, se recurre a los testimonios de ancianos de las comunidades en el mismo nivel de importancia que las citas de trabajos académicos y de documentos de archivo, jugando la función de citas de autoridad para respaldar el texto (Lozano 1987). una historia aymara que sirviera para marcar distancia con occidente y con Chile. Chipana (2002 $\mathrm{Ms})$, en un documento de carácter propositivo para el informe final, lo planteó en estos términos, denunciando la relación de poder que ha mediado entre el occidente cristiano y el pueblo aymara. ${ }^{41}$

Se pueden establecer diferencias entre este informe final y el que presentaron los atacameños. Una de ellas, es que aunque se sigue un hilo conductor que es cronológico, cada apartado aparece más discutido, incluyendo una crítica frontal a la política del Estado chileno. Otra diferencia, es que el énfasis se encuentra en el Período Republicano, tanto peruano como chileno, ambos países indicados como los responsables de la aculturación aymara. ${ }^{42}$ El concepto central de todo el texto es el de aculturación, entendido como un proceso de pérdida sostenida y causada por agentes externos: el Estado chileno, las autoridades regionales, la escuela, los profesores, la policía, entre otros. Un acoso continuo hacia la comunidad y la tradición aymara.

Se establece así una oposición de dos totalidades: la cultura aymara y la occidental, una relación en la que la primera se ha visto perjudicada. En coherencia con la visión holocáustica que se ha desarrollado en la academia, pero en una versión menos matizada, se plantea que incluso la infraestructura pone en peligro la continuidad de lo andino.

"La sola integración, gracias a la red vial y comunicaciones nacionales, y los mecanismos de participación en la sociedad y ante autoridades chilenas, junto a los factores arriba examinados, pone en peligro la permanencia de 'lo andino"." ${ }^{43}$

Juicios similares son vertidos en relación con la educación formal, asimilada directamente con los proyectos de integración planteados por el Esta-

41 Una propuesta que conserva una estructura cronológica, y en la que se recurre a frases y autores del campo cultural latinoamericano, como José Martí y Eduardo Galeano.

42 Se refleja en una visión mucho menos romántica de Bolívar, a quien se indica como el primer responsable de la individuación de las tierras comunitarias. Informe Final Preliminar, Subgrupo de Trabajo Pueblo Aymara, Arica, enero de 2003, p. 3.

43 Informe Final Preliminar, Subgrupo de Trabajo Pueblo Aymara, Arica, enero de 2003, p. 18. 
do. A ésta oponen una visión aymara que asumen portadora de valores y criterios no occidentales, desde la cual se llega a cuestionar incluso la validez de la alfabetización.

"El impacto de este proceso de enseñanza-desarraigo puede tener dos lecturas. Desde el punto de vista del Estado y los indicadores que hoy día se utilizan, puede decirse que la introducción de la escuela occidental formal redujo el analfabetismo, si tomamos como parámetros el saber leer y escribir el castellano [...] Pero este proceso también puede interpretarse como el aumento del analfabetismo cultural aymara, la pérdida del idioma materno y la pérdida del conocimiento tradicional del medio geográfico". ${ }^{44}$

Opiniones de este tipo confluyen en un enjuiciamiento mayor hacia la ciudadanía moderna que se impuso con el dominio chileno, basada en la idea fuerza de igualdad. Se denuncia en duros términos la falacia de este principio, entendiendo el proyecto de integración populista como un mecanismo de control social y como una gran fuerza desestructuradora. ${ }^{45}$ Para hacer aun más rígido el análisis, se esencializa lo "occidentalchileno", señalando, por ejemplo, que entre sus características innatas se encontraría la depredación del medio ambiente. ${ }^{46}$ Es decir, que se esencializa lo aymara pero también su opuesto, en un modelo de análisis que no permite incorporar la complejidad de fenómenos como el de la migración (de manera similar al caso atacameño), visto como una expresión más de aculturación irremediable. Lo importante no es lo que hacen los aymaras en las ciudades -espacio difuso y lejano en este informe- sino el despoblamiento de las comunidades altiplánicas.

Interpretaciones como esta son resultado de experiencias históricas concretas además de dolorosas, pero en un análisis interno de este informe, es también el resultado de un ejercicio de autoafir-

44 Informe Final Preliminar, Subgrupo de Trabajo Pueblo Aymara, Arica, enero de 2003, p. 20.

45 Este acoso constante sólo se ha visto interrumpido por episodios de resistencia, en los que también se destacan héroes aymaras, como Antonio Mollo, a principios del siglo XX. Informe Final Preliminar, Subgrupo de Trabajo Pueblo Aymara, Arica, enero de 2003, pp. 9-10.

46 Informe Final Preliminar, Subgrupo de Trabajo Pueblo Aymara, Arica, enero de 2003, p. 13. mación, un intento por construir un lugar de enunciación propio, coherente con el objetivo de establecer diferencias culturales con la sociedad chilena. Por ejemplo, al concepto de "chilenización" -ampliamente recurrido por los exponentes de la historia regional- se opone el de "desaymarización", como una forma de escribir una historia que recoja su experiencia y particular punto de vista de los procesos regionales.

"Para el Pueblo Aymara dicho período de nuestra historia, que llamaremos 'desaymarización' por ahora, fue un proceso violento, de miedo, amedrentamiento, muerte e imposición de costumbres ajenas, de intolerancia y falta de visión de las autoridades chilenas de la época, al igual como ocurriera a partir de 1492". ${ }^{47}$

Este énfasis en la oposición de mundos: el andinoaymara y el occidental-moderno, constituye un desplazamiento en la trayectoria discursiva de los aymaras, ámbito en el cual se produce una ruptura entre estos documentos y aquellos producidos durante la década pasada, en los que lejos de buscar esa distancia lo que se afirmaba era la compatibilidad de la cultura andina con la modernidad, cuestionando a esta última su desarrollo de espaldas al mundo andino. ${ }^{48}$

Tanto en el informe atacameño como en el aymara se articulan visiones sobre procesos históricos -especialmente la incorporación de estas zonas al Estado chileno- cuyo correlato material fue el despojo de las comunidades y el desarraigo, lo que junto a la pugna ideológica entre sus dirigentes (en el caso aymara), determinan análisis poco matizados, que dibujan un mundo maniqueo en el que es difícil vislumbrar la posibilidad del diálogo. No se reconoce una relación dialógica y la

47 Informe Final Preliminar, Subgrupo de Trabajo Pueblo Aymara, Arica, enero de 2003, p. 4.

48 Se llegó a proponer incluso un modelo de desarrollo "bidimensional", que definieron en los siguientes términos: "Si bien la modernidad es importante, no debe olvidarse ni relegarse el sistema andino porque debe coexistir un modelo socio-económico bidimensional, donde nuestras comunidades andinas puedan desarrollarse como sociedad con identidad propia, pero al mismo tiempo puedan insertarse con personalidad en el sistema global (...) Es posible conjugar nuestra cosmovisión junto a la sociedad actual, para alcanzar un desarrollo pertinente y consensuado". Plan Estratégico de Desarrollo Andino, Arica, 1996, pp. 9-10 (ratificado por el II Congreso Nacional Aymara en 1997). 
inserción (subordinada) de las poblaciones indígenas en varios de los proyectos emanados desde el Estado, principalmente el de la integración a partir de la igualdad ciudadana, lo que a veces tuvo manifestaciones entusiastas, como las gestiones realizadas por las comunidades altiplánicas para el mejoramiento de la infraestructura y la llegada de la escuela pública, exigiendo la presencia del Estado en lugar de rechazarlo.

Las anteriores son consideraciones de rigor histórico que no se pueden dejar de señalar, pero que para los propósitos de este trabajo no resultan ser las más relevantes, pues lo que interesa es escudriñar en la dimensión legitimadora de un relato histórico sobre la acción política de estos grupos. En ellos se desarrollan argumentos que respaldan conceptos claves de sus discursos, como la categoría de "pueblos" que poseerían una historia, una cultura y un territorio. También el término de "originarios", con el cual señalan una existencia anterior a la de la nación chilena, pero sin relegarse al pasado sino proyectándose al presente, como colectivos vigentes que han sabido sobrevivir a la embestida nacional y modernizadora. Es en este propósito que adquieren sentido las continuidades narrativas colocadas por sobre las rupturas históricas, ejercicio en el cual los olvidos y las omisiones son de la mayor importancia ${ }^{49}$, lo que determina relatos cuya naturaleza y objetivos los distancian de aquellos que son producidos en la academia. Se trata, en definitiva, de las diferencias que existen entre memoria e historia (entendiendo a esta última como disciplina y a los historiadores como miembros del campo intelectual), las cuales responden a dinámicas distintas. Ambas mantienen un estrecho vínculo con la identidad y ambas son representaciones del pasado, pero

“ (...) la primera se propone como objetivo la exactitud de la representación, mientras que la segunda no aspira sino a la verosimilitud (...) La historia se esfuerza por poner el pasado a distancia; la memoria busca fusionarse con él" (Candau 2001: 127).

49 La función del olvido en la construcción de historias, memorias e identidades ha sido un tema largamente trabajado por distintas disciplinas. Desde la filosofía, Ricoeur (2003) profundiza esta discusión.

\section{Demandas prioritarias y nuevo trato}

En los informes de verdad histórica, tanto aymaras como atacameños repiten con insistencia la palabra "pueblo" para definirse, destacando su trayectoria a través del tiempo y las características que les permiten identificarse como tales. ${ }^{50}$ Esta condición de pueblo constituye una de las demandas centrales que hoy dirigen al Estado, exigiendo ser reconocidos como tales en la Constitución Política. ${ }^{51}$ En estos documentos se señala este tipo de reconocimiento como el principal de un conjunto de demandas catalogadas como "prioritarias" o "fundamentales", matriz desde la cual se desprenden otras de carácter más específico.

Esta demanda insiste en la necesidad de distinguir a cada uno de los pueblos indígenas, de lo cual se desprende que la palabra "indígena" resulta insuficiente en estas autorrepresentaciones, pues se trata de un término genérico que no da cuenta de la heterogeneidad cultural que encierra. De ahí el sentido que adquieren una historia aymara y una historia atacameña, a través de las cuales estos grupos buscan establecer su condición de pueblo.

Aymaras: "El pueblo aymara posee una historia milenaria, una cosmovisión de vida distinta, lengua, música, danza, artesanía, tradiciones, costumbres, poblados y paisajes andinos de belleza innegable, la cual hace que el turista de todas partes del mundo desea conocer. Este es un aporte a la identidad cultural de la región y del país que la nación debe valorar". 52

Atacameños: "Queremos ser reconocidos como un pueblo, que como tal posee creencias, valores, costumbres, una historia y un territorio compartido que nos diferencia por estas particularida-

50 Insisto en que constituye una forma de autorrepresentación restringida a la élite de cada grupo (compuesta por dirigentes, profesionales y estudiantes principalmente), quienes asumen la representatividad de colectivos históricos mayores, lo que a nivel discursivo se refleja en una forma de enunciación que parte de un "nosotros" atacameño o aymara.

51 Esta demanda forma parte del movimiento indígena general, la que se viene planteando desde el retorno a la democracia, pero especialmente a partir del Congreso Nacional de Pueblos Indígenas, realizado en 1991.

52 Informe Final Preliminar, Subgrupo de Trabajo Pueblo Aymara, Arica, enero de 2003, p. 25. 
des del resto de la sociedad mayor que conforma nuestro país". 53

En este ámbito se ubica otro desplazamiento relevante en relación con la producción discursiva que antecede a estos documentos, esta vez de mayor envergadura política. Se trata del predominio que alcanzan aquí los derechos políticos asociados al concepto de pueblo y la mayor profundidad con que es tratado este último, desarrollado en su acepción política, de la cual se desprenden derechos tales como autodeterminación y territorio. Este manejo lo vuelve un concepto central en la relación que se establece con el Estado nacional y los inserta en una discusión que han venido desarrollando los movimientos indígenas en América Latina. Conscientes de este contexto, se apoyan en instrumentos de la legislación internacional que sostienen la calidad de pueblos para estos grupos, principalmente el Convenio 169 de la Organización Internacional del Trabajo sobre Pueblos Indígenas y Tribales (1989) y a la Declaración de Naciones Unidas sobre Derechos de los Pueblos Indígenas que se encuentra en proceso de elaboración. Los atacameños reconocen estar en un proceso de aprendizaje de estos instrumentos, especialmente el convenio $169^{54}$ pero sostienen con igual fuerza una demanda en la que ven la posibilidad de ampliar su margen de acción e incidir en temas relevantes, como los proyectos de desarrollo, que en estos documentos aparecen como el ámbito más importante, hacia el cual confluyen el resto de las demandas. Por su parte, los aymaras aparecen manejando este tema con un nivel de profundidad mayor, en el que han logrado predominio aquellos dirigentes urbanos más inmersos en la ideología indianista. Al parecer, esta dirección ha tenido buena recepción por parte de las bases en el último tiempo, para quienes tiene sentido hablar de autodeterminación y territorio en medio de conflictos regionales específicos que los confronta con los agentes económicos.

\footnotetext{
53 Acta Ejecutiva, San Pedro de Atacama, 20 de mayo de 2002, p. 3.

54 La Comisión de Verdad Histórica y Nuevo Trato sirvió como espacio para difundirlo, como consta en las Actas Ejecutivas: "También se entregó a los asistentes una copia del Convenio 169 de la OIT sobre Pueblos Indígenas y Tribales, explicándose su actual situación jurídica y la necesidad de que sea discutido y socializado al interior de las organizaciones indígenas" (Acta Ejecutiva, Taller de Trabajo, Ayquina, 10 de mayo de 2002).
}

"Si bien la cuestión de los derechos territoriales, hasta hace algunos años no ocupaba un papel importante en la agenda de las organizaciones aymaras, enfrascadas en este ámbito en la demanda campesinista de la regularización y saneamiento de títulos de las comunidades de tierra, se ha terminado asentando con fuerza como respuesta a los intentos de explotación de recursos naturales (pozos altiplánicos, explotación minera)". ${ }^{55}$

Del concepto de pueblo se desprenden tres cuestiones importantes que también aparecen señaladas: el principio de autodeterminación, los derechos colectivos y la noción de territorio, este último entendido como la base material sobre la cual se reproduce cada pueblo y cuya importancia es tanto simbólica como económica. Sobre esta plataforma se articula la crítica a la Ley Indígena de 1993, que habla de etnias en lugar de pueblos y de tierras en lugar de territorios. ${ }^{56} \mathrm{Un}$ instrumento que valoran, por cuanto tendió a democratizar el escenario postdictadura, pero que resulta insuficiente frente a las aspiraciones políticas actuales. La definición que hacen los atacameños de su territorio es una muestra de esta distancia.

"El pueblo atacameño reivindica los derechos sobre su territorio de ocupación ancestral, incluyendo el control y gestión de sus recursos, la protección de las aguas, los equilibrios ecológicos, su patrimonio histórico y cultural, la participación en decisiones que afecten al territorio y en los beneficios económicos de actividades que realicen terceros y la recuperación de ambientes degradados por terceros". ${ }^{57}$

En este marco se puede entender la formulación de demandas específicas, tales como una educación pertinente e intercultural, preservación y rescate de tradiciones, participación en los distintos niveles de la institucionalidad política, entre otros. Hasta otras todavía más puntuales como subsidios, prestaciones, mejoras en la infraestructura de las comunidades, becas, asesoría judicial, previsión social, entre otros. La pregunta que surge de estas exigencias es simple: ¿qué faculta a estos grupos para solicitar al Estado servicios que también an-

55 "Sistematización de las demandas y propuestas del pueblo aymara para un nuevo trato". Arica, abril de 2002, p. 4.

56 Ley Indígena (19.253), Artículos 1 y 12 respectivamente (www.derechosindigenas.cl).

57 Informe Final Preliminar, Subgrupo de Trabajo Pueblo Aymara, Arica, enero de 2003. 
helan y necesitan el conjunto de los pobres del país? La respuesta se encuentra nuevamente en el concepto de "pueblos indígenas", pues como señala Colom (1998: 122), la diferencia no otorga derechos por sí misma, sino la desventaja histórica y el atropello para el cual esta diferencia ha servido como excusa. A esto apuntan los documentos de aymaras y atacameños, en los cuales la verdad histórica enfatiza en el daño infligido por la sociedad mayor y la necesidad de repararlo como una forma de enfrentar la deuda con sus pueblos. ${ }^{58}$ Como ejemplo, cito nuevamente el Informe Final del Pueblo Atacameño (sección "nuevo trato", redactada en tercera persona).

"Los atacameños demandan ser reconocidos y respetados como uno de los Pueblos Originarios de Chile. Demandan a su vez el reconocimiento por parte de la nación chilena de los perjuicios realizados a ésta a lo largo de su historia en torno al menoscabo de su cultura y territorio, incluidos los recursos naturales que son parte de él". ${ }^{59}$

Más allá de la adhesión a estas demandas, corresponde preguntarse por sus implicancias. Una de ellas, es que el reconocimiento de estos grupos como pueblos en la Constitución Política implicaría un desplazamiento con respecto a la definición de nación chilena que contiene nuestra carta magna. Incorporar de esta manera la diversidad cultural entraña varias cuestiones sobre las cuales los actores de este diálogo no se han pronunciado. Una de ellas es que la nación ya no sería concebida en términos monolíticos y definida por exclusividad, es decir, como poseedora de rasgos compartidos por todos sus miembros y que la distinguen de las demás naciones (Palti 2003: 132), sino por la inclusión de aquellos grupos diferenciados culturalmente, en un espacio nacional de convergencia. ¿Existe conciencia de este trasfondo? Un lenguaje hasta ahora centrado en el nuevo trato a través de políticas de discriminación positiva, indica que estas implicancias no han sido tema de debate. En este mismo sentido, temas como el de la autodeterminación aparecen solamente mencionados, sin especificaciones en torno a su significado, pues invocar este principio

58 Esta lógica de la reparación ha operado como un consenso con la clase política a partir de 1990, el cual permitió la aprobación de la Ley Indígena. El mismo presidente Lagos la ha desarrollado en sus pronunciamientos sobre la materia.

59 Informe Final Preliminar, Subgrupo de Trabajo Pueblo Aymara, Arica, enero de 2003, p. 56. -más concretamente el de autonomía, que también ha sido deslizado en estos documentos- implica la creación de una institucionalidad que altera la tradición centralista del Estado chileno, lo cual indica que el potencial democratizador de estas propuestas no ha sido suficientemente advertido (Díaz Polanco 1999).

Por parte del Estado tampoco parece existir la profundidad teórica que se requiere para enfrentar un diálogo que se afirma en esta dirección, el cual además parte bloqueado por la escasa incidencia de espacios como el de la Comisión de Verdad Histórica y Nuevo Trato, que ni siquiera posee la facultad de incidir en la reformulación de un instrumento específico como la Ley Indígena. ${ }^{60}$

Sobre el reconocimiento que reclaman tanto aymaras como atacameños, es imprescindible discutir el eje de la diferencia, en ningún caso para negar su derecho a ella, sino para analizar en qué términos aparece planteada y cuáles son las posibilidades que abre. Sus discursos enfatizan en ella, pero ¿qué ocurre con el concepto de igualdad que de cuando en cuando se filtra en estos documentos?, ¿cómo se resuelve el par igualdad/diferencia? De una discusión productiva sobre este punto depende un modelo de integración justo, que respete el derecho de estos pueblos a la diferencia, pero que a la vez permita la convivencia y el diálogo no sólo con el Estado, sino con el conjunto de los sectores que conforman la sociedad nacional. ${ }^{61}$

60 La situación latinoamericana no es alentadora sobre este punto, ya que por lo general los Estados se han negado a discutir el marco nacional, dejando intactas definiciones integristas, especialmente en temas sensibles como el del territorio, con lo cual se deja el reconocimiento de la diversidad cultural en un nivel más bien retórico (Díaz Polanco 1998: 15).

61 Es interesante la aparición de esta tensión (no resuelta) en los documentos aymaras, como lo demuestra la transcripción de una cita correspondiente al Plan Estratégico de Desarrollo Aymara en uno de los documentos presentados a la Comisión de Verdad Histórica que a continuación cito: "En general, la legislación chilena está basada en la premisa equívoca de la homogeneidad social-racial, de tal manera que una ley especial indígena, si bien es un gran avance, no resulta del todo eficaz si no se reconoce la diversidad en la generalidad del quehacer legislativo (...) Desde nuestro punto de vista el problema es el desconocimiento, intencionado o no por parte del legislador de otras realidades diversas, como la nuestra, por ende el no reconocimiento de las mismas. Lo anterior atenta contra el principio de igualdad (...)" (Sistematización de las demandas, p. 2; el destacado es nuestro) 


\section{Conclusiones}

Los documentos elaborados por aymaras y atacameños en el marco de la Comisión de Verdad Histórica y Nuevo Trato contienen discursos en los cuales se establece una conexión entre la historia y las demandas que plantean al Estado. A través de un relato que reivindican como propio, se articula una autorrepresentación que los instala en el tiempo presente, con los argumentos necesarios para exigir desde políticas de reparación hasta la autodeterminación en lo que consideran sus territorios. Esto, a partir de la calidad de pueblo que tanto aymaras como atacameños se atribuyen.

En razón de los principios y argumentos que los integran, estamos frente a construcciones discursivas híbridas, que reúnen elementos provenientes del indigenismo, del desarrollismo, del indianismo, del derecho internacional y de la filosofía política. Un punto neurálgico de estos discursos, es el énfasis que colocan en el Estado como proveedor y como regulador de las relaciones sociales, reposicionándolo como un lugar de negociación, en contradicción con tendencias de las últimas décadas (la neoliberal principalmente) que niegan la legitimidad de esta mediación.

También es posible advertir en ellos nudos problemáticos que tensionan estas representaciones de lo aymara y lo atacameño, fundamentadas en la existencia de una cultura tradicional a la cual se atribuyen características fijas, pues la discusión de su situación al interior de la nación chilena los obliga a situarse en un contexto moderno y apelar a un lenguaje igualmente moderno para respaldar sus demandas. Me refiero a nociones centrales de sus discursos, como las de "pueblo" y "derechos". Esto se produce en un período de etnificación bullente, como un tipo de respuesta a conflictos nuevos producidos al calor de cambios estructurales que quitaron el piso político y económico de identidades anteriores. La modernidad aparece aquí en sus dos dimensiones, aquella instrumental que es la responsable de estas contradicciones y otra emancipadora, que provee los recursos para formular un discurso reivindicativo. Esta ubicación compleja en el campo moderno contrasta con corrientes académicas que insisten en hacer de los pueblos indígenas el símbolo de un nebuloso mundo no occidental, el cual se opondría a una modernidad descrita siempre en términos absolutos y negativos.

Tensiones de este tipo no hacen más que multiplicar los desafíos, sobre todo pensando en que se trata de un proceso que no ha concluido y que por lo mismo resulta incierto. Uno de ellos es enfrentar con eficacia un riesgo latente, como es el de la cooptación del discurso de la diferencia, tanto por parte del Estado como del mercado (¿cómo impedir que estos reclamos se rutinicen y pasen a formar parte del paisaje político?). Es una posibilidad de desenlace, pero no la única. Otra sería encauzar este debate hacia el problema de la nación, discutir su carácter unitario y promover su reformulación, un debate necesario en el que la rigidización de las identidades étnicas (otro camino posible) no tendría cabida.

\begin{abstract}
Agradecimientos Agradezco a José Luis Martínez las sugerencias y los documentos que me facilitó cuando la Comisión de Verdad Histórica y Nuevo Trato aún no concluía sus trabajos. También a María Berríos, quien amablemente tradujo al inglés el resumen de este artículo. Finalmente debo mencionar a Hans Gundermann, quien colaboró con documentación aymara correspondiente a otros períodos y con la lectura crítica de las primeras versiones de este trabajo.
\end{abstract}

\section{REFERENCIAS CITADAS}

ALBER, E., 1999. ¿Migración o movilidad en Huayopampa? Nuevos temas y tendencias en la discusión sobre la comunidad campesina en los Andes. Instituto de Estudios Peruanos, Lima.

BENGOA, J., 2000. La emergencia indígena en América Latina. Fondo de Cultura Económica, Santiago.
CASTRO, V. y J. L. MARTINEZ, 1996. Poblaciones indígenas de Atacama. En Etnografía. Sociedades indígenas contemporáneas y su ideología, J. Hidalgo, V. Schiappacasse, H. Niemeyer, C. Aldunate y P. Mege (Eds.), pp. 69-109. Editorial Andrés Bello, Santiago.

CANDAU, J., 2001. Memoria e identidad. Ediciones del Sol, Buenos Aires. 


\section{CLAUDIA ZAPATA S.}

COLMENARES, G., 1997. Las convenciones contra la cultura. Ensayos sobre la historiografía hispanoamericana del siglo XIX. TM Editores, Bogotá.

COLOM, F., 1998. Razones de identidad. Pluralismo cultural e integración política. Anthropos, Barcelona.

DE TORO, A. (Ed.), 1997. Postmodernidad y postcolonialidad. Breves reflexiones sobre América Latina. Editorial Iberoamericana, Madrid.

DIAZ POLANCO, H., 1999. Autonomía regional. La autodeterminación de los pueblos indios. Siglo XXI, México D. F.

FERNANDEZ BRAVO, A. (Comp.), 2000. La invención de la nación. Lecturas de la identidad de Herder a Homi Bhabha. Ediciones Manantial, Buenos Aires.

GUNDERMANN, H., 2000. Las organizaciones étnicas y el discurso de la identidad en el norte de Chile, 1980-2000. Estudios Atacameños 19: 75-91.

-2003. Las poblaciones indígenas andinas de Chile y la experiencia de la ciudadanía. En Mapuches y Aymaras. El debate en torno al reconocimiento y los derechos ciudadanos, H. Gundermann, R. Foerster y J. I. Vergara (Eds.), pp. 19-104. RIL Editores, Santiago.

HIDALGO, J., 1982. Fases de la rebelión indígena de 1781 en el corregimiento de Atacama y esquema de la inestabilidad política que la precede, 1749-1781. Chungara 9: 192-246.

KOONINGS, K. y P. SILVA, (Eds), 1999. Construcciones étnicas y dinámica sociocultural en América Latina. Abya-Yala, Quito.

LE GOFF, J., 1991. Pensar la historia. Modernidad, presente y progreso. Ediciones Paidós, Barcelona.

LOZANO, J., 1987. El discurso histórico. Alianza Editorial, Madrid.

MARTINEZ, J. L., 1994. Relaciones y negociaciones entre las sociedades indígenas de la región atacameña, y el Estado y la sociedad chilenos. Siglos XIX y XX. Proposiciones 24: 201-207.

MARTINEZ, N., V. GALLARDO y J. L. MARTINEZ, 2003. Presencia y representación de los indios en la construcción de nuevos imaginarios nacionales (Argentina, Bolivia, Chile y Perú 1880-1920. En Nación, Estado y cultura en América Latina, A. Castillo, E. Muzzopappa, A. Salomone, B. Urrejola y C. Zapata (Eds.), pp. 161-222. Ediciones Facultad de Filosofía y Humanidades, Universidad de Chile, Editorial LOM, Santiago.

NUÑEZ, L., 1992. Cultura y conflicto en los oasis de San Pedro de Atacama. Editorial Universitaria, Santiago.

PALTI, E., 2003. La nación como problema. Los historiadores y la "cuestión nacional". Fondo de Cultura Económica, Buenos Aires.
RENAN, E., 2000. ¿Qué es una nación? En La invención de la nación. Lecturas de la identidad de Herder a Homi Bhabha, A. Fernández Bravo (Comp.), pp. 53-66. Ediciones Manantial, Buenos Aires.

RICOEUR, P., 2003. La memoria, la historia y el olvido. Trotta, Madrid.

RIVERA, F., 1999. Construcción y reformulación de la etnicidad atacameña en el norte de Chile. En Construcciones étnicas y dinámica sociocultural en América Latina, $\mathrm{K}$ Koonings y P. Silva (Eds.), pp. 77-90. Abya-Yala, Quito.

STAVENHAGEN, R., 2000. Conflictos étnicos y Estado nacional. Siglo XXI, México D. F.

\section{Documentos}

Organización Internacional del Trabajo (OIT):

_-Convenio 169 de la Organización Internacional del Trabajo, "Convenio sobre pueblos indígenas y tribales", 1989 (www.laneta.org.apc).

Gobierno de Chile:

—_Ley Indígena ${ }^{\circ} 19253$ (www.derechosindigenas.cl).

_- Ministerios asumen compromiso con Pueblos Originarios (www.conadi.cl).

__ Ricardo Lagos Escobar, "Constitución de la Comisión de Verdad y Política del Nuevo Trato entre el Estado, sociedad y mundo indígena en Chile". Santiago, 18 de enero de 2001

—-Decreto Supremo no 19, 18 de enero de 2001.

Cristián Maquieira, Embajador, Representante Permanente Alterno de Chile ante Naciones Unidas, Intervención en el Programa de actividades del Decenio Internacional de las Poblaciones Indígenas del Mundo, Nueva York, 17 de octubre de 2002.

Documentos aymaras previos al 2003:

_-Plan Estratégico de Desarrollo Andino, Arica, 1996 (coordinado por Cornelio Chipana).

- Propuesta del Pueblo Aymara a los Candidatos Presidenciales. Consejo Nacional Aymara, 21 de noviembre e 1999.

_-Propuesta IV Congreso Nacional Aymara, Arica, 28 de octubre de 2002. Comisión IV Congreso Provincia de Iquique.

Comisión de Verdad Histórica y Nuevo Trato Grupo de Trabajo Pueblos Indígenas del Norte Subgrupo Pueblo Aymara

- Cornelio Chipana. "Elementos teóricos. Apuntes para formular procesos históricos en la relación del Estado con el Pueblo Aymara". Iquique, 19 de marzo de 2002. 
—Acta Ejecutiva, Reunión de Trabajo. Pica, 13 y 14 de abril de 2002.

- Sistematización de las demandas y propuestas del pueblo aymara para un nuevo trato". Arica, abril de 2002.

_Acta Ejecutiva, Reunión de Grupos Temáticos. Arica, 11 de mayo de 2002.

- - Acta Ejecutiva, Reunión Subgrupo Trabajo Pueblo Aymara. Arica, 30 de noviembre de 2002.

_-Acta Ejecutiva, Reunión Comisiones Temáticas Subgrupo de Trabajo Pueblo Aymara. Arica, 14 de diciembre de 2002.

_ Informe Final Preliminar. Arica, enero de 2003.

Subgrupo Pueblo Atacameño

__ Plan de Trabajo. San Pedro de Atacama, abril de 2002.

- Acta Ejecutiva Componente Nuevo Trato, ampliado de dirigentes atacameños. San Pedro de Atacama, 26 y 27 de abril de 2002.
_-Francisca Greene S., "Sistematización de las demandas indígenas atacameñas". San Pedro de Atacama, abril de 2002.

—_Acta Ejecutiva, Taller de Trabajo. Ayquina, 10 de mayo de 2002.

- Acta Ejecutiva, Taller de Trabajo. San Pedro de Atacama, 20 de mayo de 2002.

_-Acta Ejecutiva, Taller de Trabajo. Chiu Chiu, 31 de mayo de 2002.

__ Informe Final. San Pedro de Atacama, octubre de 2002.

Secretaría Ejecutiva

__ Minuta de la Secretaría Ejecutiva. "Sistematización de las propuestas y planteamientos de nuevo trato, según consta en informes de los grupos de trabajo aymara, atacameño, quechua, colla e indígenas urbanos". Santiago, marzo de 2003. 